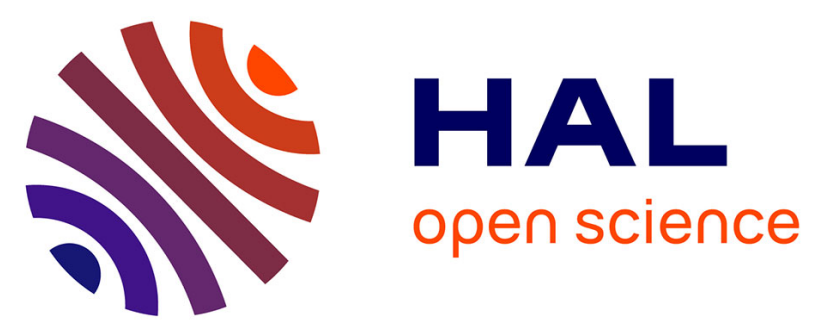

\title{
Complementing subjective with objective data in analysing expertise: A machine-learning approach applied to badminton
}

Olivier Dieu, Christophe Schnitzler, Clément Llena, François Potdevin

\section{To cite this version:}

Olivier Dieu, Christophe Schnitzler, Clément Llena, François Potdevin. Complementing subjective with objective data in analysing expertise: A machine-learning approach applied to badminton. Journal of Sports Sciences, 2020, 38 (17), pp.1943-1952. 10.1080/02640414.2020.1764812 . hal-03015592

\author{
HAL Id: hal-03015592 \\ https://hal.science/hal-03015592
}

Submitted on 19 Nov 2020

HAL is a multi-disciplinary open access archive for the deposit and dissemination of scientific research documents, whether they are published or not. The documents may come from teaching and research institutions in France or abroad, or from public or private research centers.
L'archive ouverte pluridisciplinaire HAL, est destinée au dépôt et à la diffusion de documents scientifiques de niveau recherche, publiés ou non, émanant des établissements d'enseignement et de recherche français ou étrangers, des laboratoires publics ou privés. 


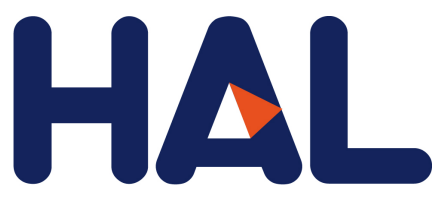

archives-ouvertes

\section{Complementing subjective with objective data in analysing expertise: A machine-learning approach applied to badminton}

Olivier Dieu, Christophe Schnitzler, Clément Llena, François Potdevin

\section{To cite this version:}

Olivier Dieu, Christophe Schnitzler, Clément Llena, François Potdevin. Complementing subjective with objective data in analysing expertise: A machine-learning approach applied to badminton. Journal of Sports Sciences, Taylor \& Francis: SSH Journals, 2020, pp.1-10. 10.1080/02640414.2020.1764812 . hal-03015592

HAL Id: hal-03015592

https://hal.archives-ouvertes.fr/hal-03015592

Submitted on 19 Nov 2020

HAL is a multi-disciplinary open access archive for the deposit and dissemination of scientific research documents, whether they are published or not. The documents may come from teaching and research institutions in France or abroad, or from public or private research centers.
L'archive ouverte pluridisciplinaire HAL, est destinée au dépôt et à la diffusion de documents scientifiques de niveau recherche, publiés ou non, émanant des établissements d'enseignement et de recherche français ou étrangers, des laboratoires publics ou privés. 


\section{Complementing subjective with objective data in analysing expertise: A machine-learning approach applied to badminton}

\section{Olivier Dieu , Christophe Schnitzler , Clément Llena \& François Potdevin}

To cite this article: Olivier Dieu , Christophe Schnitzler , Clément Llena \& François Potdevin (2020): Complementing subjective with objective data in analysing expertise: A machine-learning approach applied to badminton, Journal of Sports Sciences, DOI: $10.1080 / 02640414.2020 .1764812$

To link to this article: https://doi.org/10.1080/02640414.2020.1764812

曲 Published online: 17 Jun 2020.

Submit your article to this journal $₫$

View related articles $₫$

View Crossmark data $\nearrow$ 


\title{
Complementing subjective with objective data in analysing expertise: A machine-learning approach applied to badminton
}

\author{
Olivier Dieu (D) ${ }^{a}$, Christophe Schnitzler $\mathbb{D}^{\mathrm{b}}$, Clément Llena $\mathbb{D}^{\mathrm{c}}$ and François Potdevin $\mathbb{D}^{\mathrm{c}}$ \\ aUniv. Littoral Côte d'Opale, Univ. Lille, Univ. Artois, ULR 7369 - URePSSS - Unité de Recherche Pluridisciplinaire Sport Santé Société, F-59140 \\ Dunkerque, France; bUniversité de Strasbourg, E3S UR 1342, Faculté des Sciences du Sport, F-67000, Strasbourg, France; 'Univ. Lille, Univ. Artois, Univ. \\ Littoral Côte d'Opale, ULR 7369 - URePSSS - Unité de Recherche Pluridisciplinaire Sport Santé Société, F-59000 Lille, France
}

ABSTRACT

This study aimed to assess which combination of subjective and empirical data might help to identify the expertise level. A group of 10 expert coaches classified 40 participants in 5 different expertise groups based on the video footage of the rallies. The expertise levels were determined using a typology based on a continuum of 5 conative stages: (1) structural, (2) functional, (3) technical, (4) contextual, and (5) expertise. The video allowed empirical measurement of the duration of the rallies, and tri-axial accelerometers measured the intensity of the player's involvement. A principal component analysis showed that two dimensions explained $54.9 \%$ of the total variance in the data and that conative stage and empirical parameters during rallies (duration, intensity of the game) were correlated with axis 1, whereas duration and acceleration data between rallies were correlated with axis 2 . A random forest algorithm showed that among the parameters considered, acceleration, duration of the rallies, and time between rallies could predict conative stages with a prediction accuracy above possibility.

This study suggests that performance analysis benefits from the confrontation of subjective and objective data in order to design training plans according to the expertise level of the participants.
ARTICLE HISTORY

Accepted 16 January 2020

KEYWORDS

Performance analysis; data mining; accelerometry; conative

\section{Introduction}

According to Seifert et al. (2013), expertise can be considered the relevant ongoing co-adaptation of an individual's behaviours to dynamically changing, interacting constraints, individually perceived and encountered. It is therefore essential to understand how underpinning performance parameters interact with skill level to constrain performance. Understanding expertise (or skilful behaviour) means that the analyst should be able to outline not only the system's components, but also the interrelations that are significant to performance in order to guide learners to new adaptation according to their expertise level. Identifying the key properties of expert movement is crucial in sport coaching or teaching. Both empirical and subjective methods have been developed in a sporting context for this purpose.

With regards to subjective methods, the capacity to recognise a behavioural pattern is a general requirement of human performance in various domains, such as sports science and performance analysis (Mather \& West, 1993). For example, it has been suggested that the ability to extract higher order predicates (e.g., tactical information) from positional data and temporal relationships between individuals on field is an important part of skilled motion perception (Smeeton et al., 2004). Observation grids, used to establish typologies (Bailey, 1994), have proven particularly useful in identifying different levels of skilful behaviour (Cools et al., 2009; Williams et al., 2006). These typologies can be observed in racquet games (M. Hughes, 1998) such as tennis (Taylor \& Hughes, 1998) and badminton
(M. Blomqvist et al., 1998; M. T. Blomqvist et al., 2000; Wang \& Liu, 2012; Wang et al., 2009; Wang \& Moffit, 2009). These methods tend to evaluate the type of behaviour exhibited but fail to specify on the underlying strategy which guides the actions performed by the player.

The conative educational approach developed by Bui-Xuân (1993) in the field of sports (J. Vanhelst, Béghin, Duhamel et al., 2012) offers interesting perspectives on setting expertise-based typologies, especially sports in which strategy is paramount (Dieu et al., 2014).

Conation has been used to explore what encourages people to act and goes beyond cognition (Gerdes \& Stromwall, 2008; Gholar \& Riggs, 2004). The conative framework suggests that each individual has his/her personal conative style, i.e. a preferred method of putting thought into action and interacting with the environment (Lorgnier et al., 2018; Mikulovic et al., 2002; Vanhelst et al., 2013). In the field of sports, the purpose of the conative model is to identify what gives an athlete meaning and makes them want to act (Bui-Xuân \& Récopé, 2006).

This framework is based on the hypothesis that progress in sports is not solely a question of greater efficacity (Hastie et al., 2009), but relies also on a shift in the conative domain, i.e., a shift in the player's tactical and strategical focus (Bui-Xuân, 1993). Depending on their level of experience (i.e., "conative stage"), players may focus on the game's structural (e.g., physical abilities), functional (e.g., tactical) or technical aspects (e.g., technical skills). This model identifies different forms of impulse, or impetus, which guide actions. The impetus is 
determined by the player's progress throughout the three components of the model (structural, functional, and technical). These three components constitute the guiding principle which organises each conative stage. Five conative stages are proposed for the classification of players, from novice to expert: (1) structural, (2) functional, (3) technical, (4) contextual, and (5) expertise. All these stages are characterized by a combination of the abovementioned components (physical, technical, tactical), but in each stage one of the components dominates the other, as described by Bui-Xuân (1993). The criterion of the conative classification has been applied to athletic activity to classify participants (Vanhelst et al., 2012) and more recently in badminton (Dieu et al., 2014). In badminton, on Stage 1 (structural), the player's intent is to send back the shuttlecock, therefore physical abilities are mobilised first. Once the player has solved the problem of returning the shuttlecock, he/she begins playing in the game space, with the aim of forcing the opponent to move. At this point, the player is already in a "tactical" or functional stage (Stage 2), even if the techniques for handling the shuttlecock are basic. On Stage 3 (technical), the player loses in functionality what he/she gains in technical efficiency, given that this stage concerns the stabilisation of the driving skill. It is not until the next level (Stage 4) that the player is able to "contextualise" his/her technique in a sequence of strokes, therefore this stage is again tactical. The highest or expert stage (Stage 5) is characterised by the optimal mobilisation of structural, functional, and technical abilities in order to form the player's style of play. Conative classification that modelizes five foci (or intended goals) makes it possible to think of expertise within the framework of the complex systems approach (Ibáñez-Gijón et al., 2017; Seifert et al., 2013). The latter adopts a more integrated approach to qualitative descriptions of the changes in the physical activity from novice to expert. The conative stage is therefore a subjective way of characterizing expertise based on a classification that reflects not only the mechanical aspect of expertise (technical skills, tactical indicators or physical variables), but also the specific relationship between mechanical and functional aspects of expertise (the focus that guides players).

Typologies are therefore a highly useful tool to identify complex behaviours. However, typologies have received some criticism (Bailey, 1994) for three reasons: they are often based on somewhat arbitrary criteria, they are essentially static, and they can pose significant reliability challenges. Such classification based on human perceptions and judgements which may limit their use in scientific studies (Knudson, 2013). Developing a strong strategy to analyse performance in such sporting contexts requires complementing these subjective assessments with more objective methods as notational (M. Hughes \& Franks, 2004), kinematic (Hamill \& Selbie, 2004) and kinetic methods (Caldwell et al., 2004). Performance analysis is a complex task which relies on a wide array of indicators. Qualitative methods offer interesting perspectives to outline skill level, but present issues of reliability and validity (Bailey, 1994). Quantitative methods, on the other hand, provide an insight on the kind of tactic used with notational analysis, as well as providing a precise description of how a movement is performed (kinematic and kinetic analysis). However, when used in isolation, these methods fall short in characterising skilful performance. Finding out how qualitative and quantitative data relate to one another is therefore essential to sport analysis (M. D. Hughes \& Bartlett, 2002). In badminton, few studies have attempted to establish an analysis framework that encompasses both forms of analysis. Many authors (AbianVicen et al., 2013; Cabello et al., 2004; Cabello Manrique, 2003; H.-L. Chen \& Chen, 2008; Faude et al., 2007; Ming et al., 2008) used notational analysis, but the scope of those studies was limited to a description of high-level play according to age, sex or a change in scoring rules. Other authors examined how kinetic data, assessed by accelerometry, could be used as a non-invasive method to account for tactic used throughout the play in a real-game conditions (Dieu, 2012; Dieu et al., 2014; Silva et al., 2015), but a link with a more subjective component of skilful behaviour was not established. This accelerometry measurement appears to be particularly relevant in a 3-dimensional sport characterized by continual changes in movement direction and a high frequency of "stop and go" manoeuvres (M. Phomsoupha \& Dor, 2015). This method provides access to physical activity quantification and temporal data (rally time, match duration) reflecting the tactical aspect of match management (M. Phomsoupha \& Laffaye, 2015).

These approaches point to the fact that novices and experts differ not only in their physical characteristics and skillsets, but also their typical focus during games, which is born from the interactions between all these characteristics. The original nature of this data collection is that it relies on both empirical and subjective data, which requires the use of a specific data analysis method. Machine learning methods offer an interesting perspective to bridging this gap. These computational methods use a different set of algorithms to make predictions based on data (Kohavi \& Provost, 1998), and have proven useful in sporting contexts for their ability to objectify typologies by connecting physiological and biomechanical data with subjective assessments from experts during safety swim tasks (Schnitzler et al., 2014). In this respect, these unconventional methods (as compared to linear ones) could be useful for two reasons. First, because they allow for feature selection, thereby ensuring that potentially unnecessary variables (or features) are not present in the final model. Second, machine learning algorithms are capable of fitting non-linear data, as is often the case in studies on expertise (Seifert et al., 2017). Lastly, these procedures split the dataset and perform the analysis on independent sub-settings of the data, which helps minimize overfitting.

Therefore, the aim of this study is to examine the relationship between the judgement of expertise levels and objective measurement in order to understand the complexity of performance and progression in badminton using machine learning.

\section{Materials and methods}

\section{Participants}

Forty French participants took part in this study. Their characteristics are summarised in Table 1. Participants were fully informed before providing written and informed consent. The University Ethics Committee approved all experimental procedures. 
Table 1. Characteristics of participants.

\begin{tabular}{lccc}
\hline Participants & Total & Males & Females \\
\hline $\mathrm{N}$ & 40 & 31 & 9 \\
Age (years) & $22[17-37]$ & $22[17-37]$ & $21[18-26]$ \\
Height $(\mathrm{cm})$ & $176[160-195]$ & $178[160-195]$ & $168[162-176]$ \\
Weight $(\mathrm{kg})$ & $70.0[52.0-100.0]$ & $73.0[53.0-100.0]$ & $59.4[52.0-70.0]$ \\
\hline
\end{tabular}

Continuous data are presented as mean [range].

\section{Subjective assessment of the skill level of participants}

Participants were classified into five groups according to their performance levels. Every participant had to play one set of 21 points against an opponent from the same performance level group. To avoid a significant imbalance between players, each set in which the loser's score was below 11 points was rejected from the analysis. All players were videotaped and classified into one of five conative stages: (1) structural, (2) functional, (3) technical, (4) contextual, and (5) expertise, using the conative criteria developed for curriculum by Dieu et al. (2014). This conative curriculum is described in Table 2.

This theoretical conative classification grid was certified by a video testing of the ten badminton specialists on the 2011 national committee, in charge of recruiting physical education teachers (Dieu, 2015). For the present study, two expert analysts classified the players according to the conative stages of each player independently. Chronbach's alpha was considered excellent $(\alpha=0.91)$. But when a disagreement occurred between the analysts, the video was viewed again conjointly. If a consensus couldn't be reached, the participant was discarded from the analysis. This was the case for 2 participants. In total, 50 sets between the 40 players of equivalent performance level were selected for this analysis, which provided 1806 rallies (Table 3).

\section{Notational analysis}

Video recordings of each game were used to investigate the duration of each rally, which were categorised as short $(<4 \mathrm{~s})$, medium (4-7 s), long (8-11 s) of very long (>11 s) (Table 3). We also measured the duration of rallies and the duration between rallies and calculated a ratio: time of rallies/time between rallies (T_ratio) to quantify the percentage of playing time during a game (H.-L. Chen \& Chen, 2008).

\section{Kinetic variables}

Each participant wore an accelerometer while playing one set of badminton (a 21- point "tie breaker" without overtime). The only instruction given was "play like you're in a real game". Accelerometer was attached to an elastic belt at the base of the spine. The GT3X ${ }^{\oplus}$ accelerometry monitor (Pensacola, FL), measures magnitude vectors on three axes (VM_X: vertical, VM_Y: mediolateral, and VM_Z: anteroposterior). This technology was proven valid and reliable (Craig et al., 2003; De Jonge et al., 2007) to estimate energy expenditure (Chu et al., 2007; J. Vanhelst et al., 2010). Accelerometers allow subjects' physical activity to be evaluated on the basis of a mechanical measurement of movements (K. Y. Chen \& Bassett, 2005); the frequency, duration and intensity of the physical effort were thus recorded. Results are expressed in "counts." The quantity of physical activity is calculated in terms of vector magnitude (VM), which is the square root of the sum of the squares of each axis (VM_X, VM_Y and VM_Z) of data (counts). We determined the magnitude vector during the rallies (VM_R), between rallies (VM_BR) and calculated the ratio VM_R/VM_BR (VM_ ratio) as an indicator of the difference in activity between those parts of the game.

\section{Statistical analysis}

We used a typical machine learning procedure for this study, following the machine-learning examples provided by Lantz (2019). This statistical analysis consisted of five steps:

Step 1: An exploratory analysis first examined to what extent each variable related to the others. We used Spearman's correlation coefficient in order to examine the strength and the direction of the link between the conative stages and the other variables of interest. We then applied a Kaiser-Meyer-Olkin test (KMO) and a Bartlett test. The correlation matrix is fit to apply exploratory analysis when

Table 2. Description of conative classification criteria for badminton player according to Dieu et al. 2014.

\begin{tabular}{|c|c|c|}
\hline Conative stages & Behaviour description & Classifying indicators \\
\hline $\begin{array}{l}\text { Stage } 1 \\
\text { Criterion: structural } \\
\text { Conation = returning the } \\
\text { shuttle- cock }\end{array}$ & $\begin{array}{l}\text { The player is the returner. He/she will return the shuttlecock to the other } \\
\text { side of the net regardless of where it lands. The shuttlecock is seen as } \\
\text { an obstacle. }\end{array}$ & $\begin{array}{l}\text { Long sending back-central axis. } \\
\text { No status differentiation between opponent and } \\
\text { defender. Only concern: to send shuttlecock the other } \\
\text { side of the net. }\end{array}$ \\
\hline $\begin{array}{l}\text { Stage } 2 \\
\text { Criterion: functional } \\
\text { Conation = directing the } \\
\quad \text { shuttlecock }\end{array}$ & The player is a dispatcher, seeking for free space to send the shuttlecock. & $\begin{array}{l}\text { Trajectory variations. It forces the opponent to run after } \\
\text { the shuttlecock. }\end{array}$ \\
\hline $\begin{array}{l}\text { Stage } 3 \\
\text { Criterion: technical } \\
\text { Conation = making a winning } \\
\text { stroke }\end{array}$ & $\begin{array}{l}\text { Technical application. The player seeks to find himself in a favourable } \\
\text { position for smashing the shuttlecock but does not re-position him/ } \\
\text { herself after hitting. }\end{array}$ & $\begin{array}{l}\text { Smash or drop-in attack. Pause in re-positioning to } \\
\text { observe the result of action. }\end{array}$ \\
\hline $\begin{array}{l}\text { Stage } 4 \\
\text { Criterion: contextual } \\
\text { Conation = tactical sequence }\end{array}$ & $\begin{array}{l}\text { Technical-tactical sequence. The player develops tactical plans, strategies } \\
\text { of attack and defence that combines the search for free space and } \\
\text { opportunities to spike the shuttlecock powerfully. }\end{array}$ & $\begin{array}{l}\text { Re-positioning directed after hitting (sequence). Playing } \\
\text { in interception. }\end{array}$ \\
\hline $\begin{array}{l}\text { Stage } 5 \\
\text { Criterion: expertise } \\
\text { Conation = force your game } \\
\text { on the opponent }\end{array}$ & $\begin{array}{l}\text { In addition, players at this stage are capable of adapting their game- } \\
\text { power balance and the playing style of their opponent. }\end{array}$ & $\begin{array}{l}\text { Mobilises his/her own structure and techniques } \\
\text { according to his/her own playing style. }\end{array}$ \\
\hline
\end{tabular}


Table 3. Number and distribution of rallies played per conative stage.

\begin{tabular}{|c|c|c|c|c|c|c|c|c|}
\hline Conative stages & Sets & Males & Females & Rallies (N) & $\begin{array}{l}\text { Short } \\
(<4 \mathrm{~s})\end{array}$ & Medium (4-7 s) & $\begin{array}{r}\text { Long } \\
(8-11 \mathrm{~s})\end{array}$ & $\begin{array}{l}\text { Very long } \\
(>11 \mathrm{~s})\end{array}$ \\
\hline Structural & 10 & 4 & 6 & 372 & 105 & 161 & 62 & 44 \\
\hline Functional & 10 & 10 & 0 & 373 & 89 & 208 & 65 & 11 \\
\hline Technical & 10 & 6 & 4 & 347 & 50 & 233 & 52 & 12 \\
\hline Contextual & 10 & 10 & 0 & 372 & 61 & 209 & 66 & 36 \\
\hline Expert & 10 & 10 & 0 & 342 & 41 & 125 & 90 & 86 \\
\hline
\end{tabular}

$\mathrm{KMO}>0.5$ and if the Bartlett test was statistically significant $(p<.05)$. We used a corrplot toolbox in $\mathrm{R}$ software for this part of the analysis

Step 2: A principal component analysis was performed to examine the dimensionality of the data. For this analysis, we considered vector magnitude during rallies (VM_R) and vector magnitude between rallies (VM_BR) as supplementary variables, being a linear combination of the other accelerometric variables. We used FactoMiner in $\mathrm{R}$ software for this part of the analysis.

Step 3: We used a Random Forest Supervised Learning algorithm (Breiman, 2001) with conative stages as a dependent variable to examine to which extent an algorithm can predict the conative stage solely on the basis of notational and kinetic variables. For this purpose, a feature selection through a wrapper algorithm was performed to determine which of the variables are relevant to classifying the conative stages. We used the Random Forest toolbox in R software for this part of the analysis.

Step 4: As normality of the residual's distribution (Jarque-Bera test) and homoscedasticity (Levene Test) were not met in the considered parameters, we used the Kruskall-Wallis test to outline, among the quantitative variables of interest, which one changed significantly as a function of the conative stage. The difference among the conative stages was more specifically examined using a pairwise Wilcoxon test. The difference was considered significant when $p<0.05$. We computed etasquared ( $n 2$ ) effect sizes which were labelled as small [0.02-0.12], medium [0.13-0.25], and large [0.26 and above] (Cohen, 1988). We used $\mathrm{R}$ software for this part of the analysis.

Step 5. We tested how 22 classifiers algorithms could predict the conative stage based on these selected variables. We used a 5-fold cross validation method to avoid overfitting (Moore \& Lee, 1994), and used the "classification learner" Matlab toolbox. The algorithm presenting the best percentage of overall classification was selected. This algorithm aims to show to which extent quantitative data are related to the subjective judgement of the conative stages. Using the confusion matrix, the classifier was considered successful in complementing subjective assessment if it performed better than chance, that is, over $20 \%$ correct classification (given that there are 5 conative stages).

\section{Results}

\section{Step 1}

The data seem to be fit for multiple correlation analysis, since $\mathrm{KMO}=0.7$ (considered as acceptable), and Bartlett test was significant $(p<.05)$. Table 4 shows that conative stages are correlated
Table 4. Spearman coefficients of correlation between conative stages and quantitative variables of the study.

\begin{tabular}{lc} 
& Conative stages \\
\hline Duration of the rallies (s): T_R & $0.19^{*}$ \\
VM rallies: VM_R & $0.65^{*}$ \\
VM_X (rallies): X_R & $0.60^{*}$ \\
VM_Y (rallies): Y_R & $0.52^{*}$ \\
VM_Z (rallies): Z_R & $0.54^{*}$ \\
Between-rallies duration (s): T_BR & $0.23^{*}$ \\
VM between rallies: VM_BR & $-0.25^{*}$ \\
VM_X (between rallies): X_BR & $-0.25^{*}$ \\
VM_Y (between rallies): Y_BR & $-0.19^{*}$ \\
VM_Z (between rallies): Z_BR & $-0.18^{*}$ \\
Duration Ratio: T_ratio & $\mathrm{NS}$ \\
VM Ratio: VM_ratio & $0.59^{*}$ \\
\hline
\end{tabular}

* significantly correlated with $\mathrm{p}<.05$

positively with VM during rallies $(\mathrm{R}=0.65, \mathrm{p}<.05)$, in all plans. Conversely, it is negatively correlated with VM between rallies.

\section{Step 2: principal component analysis (PCA)}

The PCA showed that dimension 1 and 2 explained $54.9 \%$ of the total variance (respectively $32.6 \%$ for dimension 1 and $22.3 \%$ for dimension 2). The plotted representation on factors 1 and 2 (Figure 1) also suggested that parameters of acceleration during rallies and conative stage were well projected on axis 1, whereas parameters of acceleration between rallies were better projected on axis 2 .

\section{Step 3. Supervised learning}

As can be seen in Figure 2 and Table 5, all features did contribute to predicting the subjective conative stage, but not with the same significance. The wrapper method for feature selection shows that this is VM_ ratio which, by far, contributes the most to the classification, followed by kinetic parameters during the rallies (VM_R), the duration of the rallies, then all variables related to non-game (kinetic and duration). Table 5 shows that $T_{-}$ratio contribution to determine the conative stage is more than the contribution that would have been made by a random variable, even if its contribution is low. For this reason, we kept it in the next stage to build the prediction model.

\section{Step 4. Main descriptors of conative stages}

Results from the Kruskall-Wallis test show that all selected parameters differed as a function of the conative stage.

Pairwise Wilcoxon shows accelerometric parameters during the game, and also the ratio magnitude vector during rallies/magnitude vector between rallies (VM_ratio) 


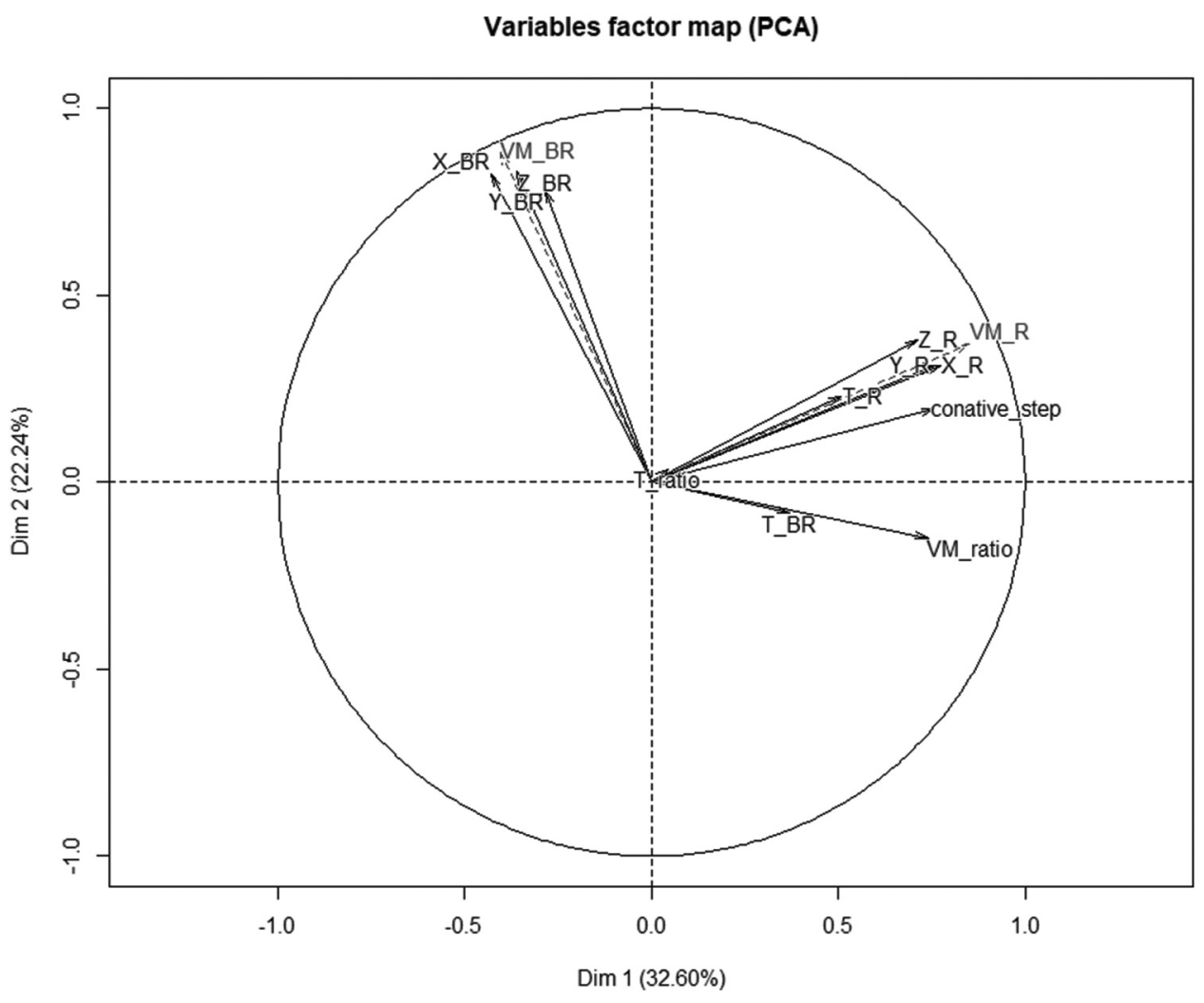

Figure 1. Organisation of the variables on the first factorial plan.

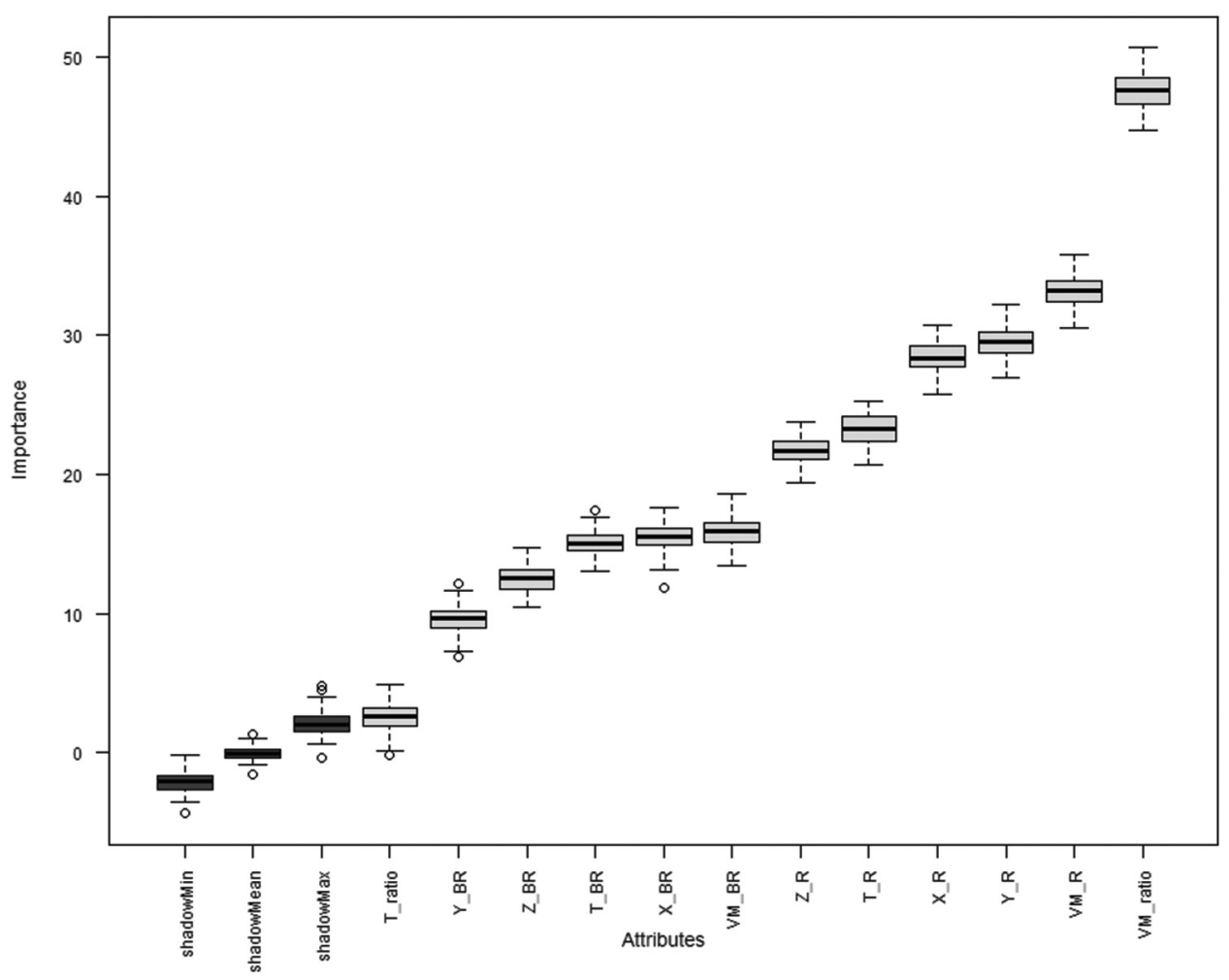

Figure 2. Importance of the different parameters in explaining the conative stage (from random tree analysis).

increased from stage to stage and had large effect sizes. As can be seen in Table 7 , the duration of the rally increases and acceleration between rallies in $X, Y, Z$ decreases but only in stage 5 (expert), with small effect sizes. Ratio time (T_ratio) (small effect) and between rallies duration have a bell-shaped curve (medium effect). 
Table 5. Importance of the various quantitative indicators in explaining the conative stage.

\begin{tabular}{lcc}
\hline Variable & Mean importance & Decision \\
\hline VM_ratio & 47.7 & Confirmed \\
VM_R & 33.2 & Confirmed \\
Y_R & 29.5 & Confirmed \\
X_R & 28.4 & Confirmed \\
T_R & 23.2 & Confirmed \\
Z_R & 21.7 & Confirmed \\
VM_BR & 15.9 & Confirmed \\
X_BR & 15.4 & Confirmed \\
T_BR & 15.0 & Confirmed \\
Z_BR & 12.5 & Confirmed \\
Y_BR & 9.5 & Confirmed \\
T_ratio & 2.5 & Confirmed \\
\hline
\end{tabular}

Step 5. Prediction of the conative stage based on the 12 best predictors

According to the previous results, all variables were included to calculate the predictive model. The 22 classifiers trained had a range of $45.1 \%$ to $57.7 \%$ of correct classification of subjective conative stages. The quadratic support vector machine algorithm performed best and was therefore chosen for the confusion matrix.

All classes were predicted with a true positive rate superior to chance (in this case, 20\% given that there are 5 conative stages).

The rate of true positive varied among classes, proving more reliable for class 5 ( $72 \%$ of true positive) and less for class 3 (25\% positive rate).

It is also interesting to note that most of the cases of misclassification could be found in the immediate neighbourhood of the true class. For example, class 3 has a misclassification rate of $76 \%$, but when adding its two neighbours, this rate fell to $44 \%$. This shows that the classifier performs rather fairly.

\section{Discussion}

The objective of this study was to examine to which extent selected notational and kinetic variables could relate to conative stages obtained using a more subjective but holistic approach. The main results show that VM_ratio is the most powerful predictor of the conative stage, but that both accelerometric and notational data are important in differentiating among conative stages. More specifically, using all twelve parameters helped to classify the conative stage with an accuracy above chance, ranging from $24 \%$ for "technical" stage to $75 \%$ for "expertise" stage.

Badminton is a complex sport, in that many parameters such as physical, physiological, psychological, tactical and affective variables might influence performance level. Our data show an excellent overall reliability level among observers in the use of the conative stage observation grid. However, this result does not reveal much about how observation relates to empirical data, which is why these relationships were analysed. Our first set of analysis-based correlations show that acceleration and notational data during rallies are positively correlated with the conative stage, whereas this correlation is negative between rallies. This result is in accordance with previous studies showing that (1) experts exhibited a higher intensity of acceleration vector (M. Blomqvist et al., 2000); and (2) management of resting time relates to expertise level (O'Donoghue \& Ingram, 2001; M. Phomsoupha \& Laffaye, 2015). On the other hand, the principal component analysis showed that during rallies, parameters (acceleration and time) are more related to expertise than between-rallies parameters. This apparent orthogonality between within- and between-rallies parameters questioned the relevancy of keeping all these 12 parameters in a performance analysis. To examine this specific point, we decided to use Supervised Learning procedures to (1) see if those quantitative data could be considered as features of the conative stage, using the Random Forest feature selection algorithm, (2) to examine how empirical data changed as a function of conative stage, and (3) to examine to which extent machine learning algorithms could predict the conative stage based on those quantitative measurements, bearing in mind that those data were collected separately.

Feature selection showed that both within and between rallies parameters are related to the conative stage. Accelerometric data seem to be the most important predictor of the conative stage. Our results indicate that, the better the conative stage, the higher the overall VM_R. More specifically, it seems that the activity is higher in the three planes of motion: $X \_R$ accounts for the acceleration in the vertical plane, $Y \_R$ in the medio-lateral plane accounting for side stepping (very specific in badminton), and Z_R in antero-posterior plan. This shows that players in higher conative stages tend to take advantage of all three planes in space to play faster and break the game of the opponent. Interestingly, the predictor with the highest load was the VM_ratio which increased significantly from stage to stage. As it showed that imbalance between VM during rallies and VM between rallies increased, we considered that as an indicator of game management. Those results confirmed past literature which showed that apart from technical repertoire, the capacity to generate large acceleration in the three planes of motion (Jaworski et al., 2017; Lieshout \& Lombard, 2003; Raman \& Nageswaran, 2013; Tiwari et al., 2011), and the ability to manage energy resources (Fahimi \& Vaezmousavi, 2011; M. Phomsoupha \& Laffaye, 2015) explain skill level in badminton, "one of the fastest and most demanding racket sports" (Lees, 2003; Reilly, 1990). Interestingly, as can be seen from the feature selection, notational parameters such rally time (T_ratio, $T_{-} B R, T_{-} R$ ) also contributed to the overall explanation of the conative stage, but its relationship with the conative stage seems more complex and non-linear.

As all parameters were confirmed to relate to the conative stage, we sought to examine how expertise began to emerge as the learner progressed. The Pairwise Wilcoxon test results suggest that each conative stage may be characterised differently.

Players at stage 1 are characterised as having the lowest acceleration rate during rallies and the lowest ratio VM rallies/ VM between rallies. Low values for both these parameters suggest a low involvement in the game, which may explain the lack of need for game management.

Players at stage 2 and 3 are characterised by a higher vector magnitude during rallies, but also higher VM_ratio, and between rallies duration as compared to stage 1 . Stage 3 


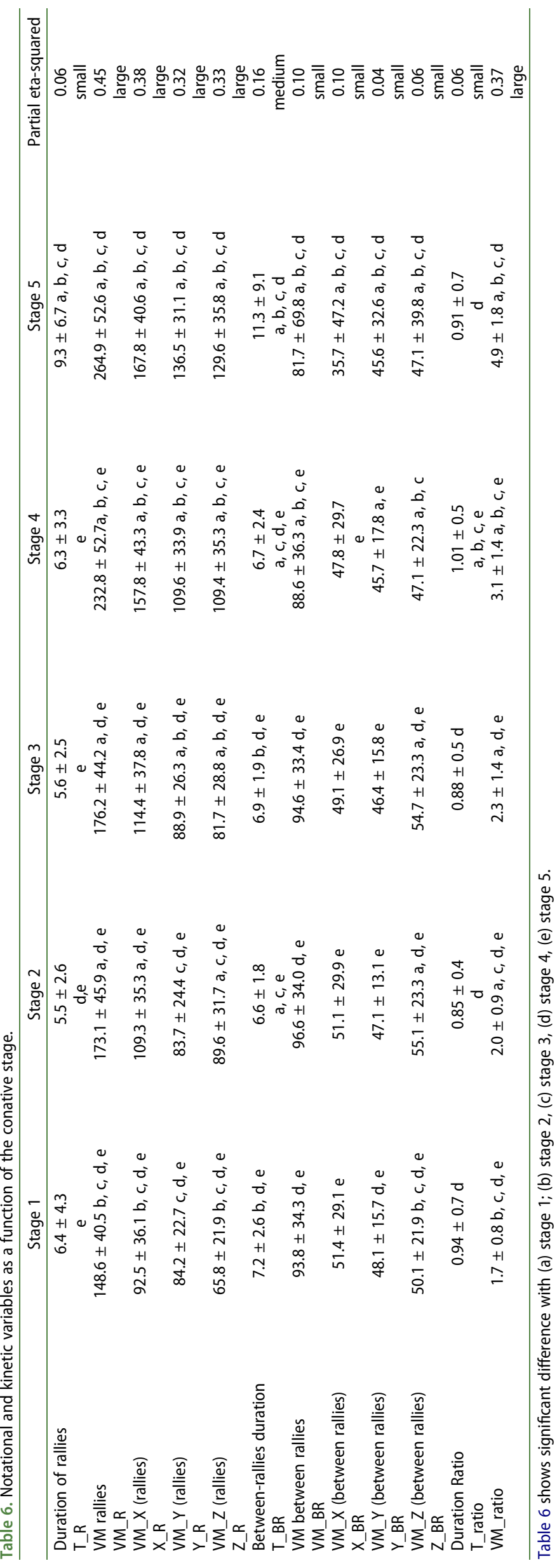


Table 7. Confusion matrix: classification of subjective conative stages.

\begin{tabular}{|c|c|c|c|c|c|c|}
\hline \multicolumn{7}{|c|}{ Predicted conative stages } \\
\hline True & & 1 & 2 & 3 & 4 & 5 \\
\hline conative & 1 & $55 \%$ & $31 \%$ & $10 \%$ & $3 \%$ & $1 \%$ \\
\hline stages & 2 & $19 \%$ & $53 \%$ & $16 \%$ & $11 \%$ & $2 \%$ \\
\hline & 3 & $22 \%$ & $41 \%$ & $24 \%$ & $11 \%$ & $2 \%$ \\
\hline & 4 & $6 \%$ & $21 \%$ & $14 \%$ & $45 \%$ & $14 \%$ \\
\hline & 5 & $5 \%$ & $3 \%$ & $4 \%$ & $17 \%$ & $72 \%$ \\
\hline
\end{tabular}

players differ from those of stage 2 due to the greater difference in acceleration rates between play and non-play, as VM_ratio increases significantly, although the difference is small ( 300 ms). This suggests that energy involvement becomes more important, which implies the need for more recovery time. More specifically, Z_R (anteroposterior movement) increases significantly from stage 1 to stage 2, whereas Y_R (mediolateral), which accounts for side-stepping displacement, is significantly higher in stage 3. This interpretation remains speculative, however, and would require further studies to be confirmed.

Players at stage 4 differ from those of stage 3 due to both the greater difference in acceleration rates between play and non-play (VM_ratio increases significantly), and the shorter relative recoveries (T_ratio). At that stage, these data suggest that energy involvement might be the players' main feature, implying both a lower energy involvement between rallies and a more active behaviour, the aim of which is to put more temporal pressure on the opponent to win the match.

Players at stage 5 are characterised by having the longest rally durations, the greatest acceleration magnitude during rallies and the highest VM_ratio of all the players but the longest between rallies duration. Energy involvement is also very high, but those data suggest that game management becomes more important: those players are not only recovering exhibiting lower VM during recovery periods, but also using longer times between rallies.

The variable VM_ratio, which represents the ratio between acceleration during rallies and acceleration within rallies, is of particular interest as it has the highest, mean significance according to Table 4. Interestingly, it does not seem to evolve in a linear manner. It increases regularly from stage 1 to stage 3 $(+0.3)$, and then increases dramatically at stage $4(+0.8)$ and 5 $(+1.8)$. The typology provided to the analyst to determine the conative stage stated that participants at stage 1 focus on means to return the shuttlecock into the field. This might explain why acceleration within and between rallies barely differs. Participants at a higher conative stage seem to be more oriented towards taking advantage of their opponent's lack of movement (functional stage), or by speeding up the exchange by using new techniques such as a "smash" (technical stage). At even higher conative stages (4 and 5), those data confirm the ability of the players to reposition themselves quickly, thus raising their ability to defend their playing field, as rally durations appear to increase.

All these results show how kinetic and spatio-temporal parameters relate to the conative stage and performance levels in badminton. But to which extent can those quantitative data predict the conative stage? To answer this question, we used another set of machine learning algorithm. Our results indicate that the quadratic SVM classification algorithm can classify the data according to the conative stage with a better rate of classification than chance. This suggests that subjective videobased analysis could benefit from more objective measurement to classify the expertise level of badminton players according to conative levels. Thus, the accelerometer's objective data could complement a technical assessment provided by the coach.

However, there are some factors which limit the scope of this study. First, it was not possible to have all participants involved playing each other once again. This would have been the most objective way to classify our population according to performance level. However, there is no doubt that group 5 (expert), and group 4 (contextual), who were respectively national and regional level players, could be clearly hierarchised according to their ranking. Also, players in the first conative stage (structural) were real beginners, therefore of a performance level lower than all the other groups. We agree, however, that stage 2 and 3 were more difficult to determine according to the subjective grid. This factor might explain why these groups had such a bad classification rate on the confusion matrix ( $24 \%$ and $53 \%$ respectively). It is interesting, however, to note that if group 2 and 3 were amalgamated, the correct classification rate would climb to $\sim 65-69 \%$, as most of the players in this group were misclassified in the other conative stage. Further study should determine whether more specific indicators should be developed to account for these respective conative stages.

Second limitation: Technical parameters such as stroke positions of the shots were not included in the study. We believe that there is a major gap in this study, which, if addressed, could further characterise those conative stages. However, we decided to limit this study to the simple parameters of time and acceleration in order to demonstrate that subjective classification based on the conative stage had an empirical basis. We trust that the approach which we promoted, that is, using machine-learning techniques shows how various sets of variables, both qualitative and quantitative, can account for performance level, may be an interesting option for examining more parameters which could be included in this study, even on an individual level.

Third limitation: Population size might also be an obstacle to drawing general conclusions from the results. However, we compared groups with different expertise levels, which meant that we needed a balanced design between conative stage groups. Moreover, this number is typical for studies on motor expertise (Schnitzler et al., 2011; Seifert et al., 2018).

Fourth limitation: There was no distinction based on sex in this study, which potentially reduces the success rate of the confusion matrix. Although male participants have an advantage due to better physical abilities (Cabello et al., 2004), badminton remains a complex sport in which skill can compensate for physical differences. From a conceptual point of view, the conative stage model only differentiates people based on their expertise levels, which is why we decided to establish our group based solely on this factor and not on a competition that would have ranked players from the least to the most proficient performer.

Fifth limitation: Qualitative and quantitative data are related, but do not establish the direction of the link. For example, are 
rhythm and acceleration consequences of the conative stage, or are they the parameters on which judgement on the conative stage is established? Such questions also call for further investigation. Nonetheless, the study provides an empirical means for identifying a player's conative stage, allowing for such investigation.

\section{Conclusion}

This study sought to establish a relationship between performance level and expertise level using a qualitative typology involving kinetic and notational indicators of performance. Our main findings were that quantifying acceleration is key to further objectifying the conative stages, and that qualitative and quantitative parameters actually complement one another other. We also suggested a methodology for analysing expertise levels that could be relevant when designing performance analysis tools in sports with a high degree of uncertainty. We were able to show which parameters could be more specifically targeted as a function of a participant's conative stage. Overall, the study advocates designing performance analysis settings by complementing selected subjective observations with empirical data.

\section{Disclosure statement}

We declare no potential conflict of interest for this research.

\section{ORCID}

Olivier Dieu (ID http://orcid.org/0000-0002-6936-5273

Christophe Schnitzler (iD http://orcid.org/0000-0002-3801-8789

Clément Llena (iD http://orcid.org/0000-0002-9571-617X

François Potdevin (D) http://orcid.org/0000-0002-6060-1698

\section{References}

Abian-Vicen, J., Castanedo, A., Abián, P., \& Sampedro, J. (2013). Temporal and notational comparison of badminton matches between men's singles and women's singles. International Journal of Performance Analysis in Sport, 13(2), 310-320. https://doi.org/10.1080/24748668.2013.11868650

Bailey, K. (1994). An introduction to classification techniques. In M. LewisBeck (Ed.), Typologies and Taxonomies: An introduction to classification techniques (pp. 1-16). SAGE Publications Inc. https://doi.org/10.4135/ 9781412986397

Blomqvist, M., Luhtanen, P., \& Laakso, L. (1998). Validation of a notational analysis system in badminton. Journal of Human Movement Studies, 35 (3), 137-150.

Blomqvist, M., Luhtanen, P., \& Laakso, L. (2000). Expert-novice differences in game performance and game understanding of youth badminton players. European Journal of Physical Education, 5(2), 208-219. https:// doi.org/10.1080/1740898000050207

Blomqvist, M. T., Luhtanen, P., Laakso, L., \& Keskinen, E. (2000). Validation of a video-based game-understanding test procedure in badminton. Journal of Teaching in Physical Education, 19(3), 325-337. https://doi. org/10.1123/jtpe.19.3.325

Breiman, L. (2001). Random forests. Machine Learning, 45(1), 5-32. https:// doi.org/10.1023/A:1010933404324

Bui-Xuân, G. (1993). Préparation aux concours de recrutement des enseignants d'EPS. In G. Bui-Xuân \& J. Gleyse (Eds.), Enseigner l'éducation physique et sportive (pp. 62-83). Editions AFRAPS.

Bui-Xuân, G., \& Récopé, M. (2006). Tendances et conations- le sens en action. In G. Carlier, D. Bouthier, \& G. Bui-Xuân (Eds.), Intervenir en éducation physique et en sport: Recherches actuelles (pp. 230-236). Presses Universitaire de Louvain.
Cabello, D., Padial, P., Lees, A., \& Rivas, F. (2004). Temporal and physiological characteristics of elite women's and men's singles badminton. International Journal of Applied Sports Sciences, 16(1), 1-12.

Cabello Manrique, D. (2003). Analysis of the characteristics of competitive badminton. British Journal of Sports Medicine, 37(1), 62-66. https://doi. org/10.1136/bjsm.37.1.62

Caldwell, G. E., Robertson, D. G. E., \& Whittlesey, S. N. (2004). Forces and their measurement. In D. G. E. Robertson, G. E. Caldwell, J. Hamill, G. Kamen, \& S. N. Whittlesey (Eds.), Research methods in biomechanics (pp. 73-102). Human Kinetics.

Chen, H.-L., \& Chen, T. C. (2008). Temporal structure comparison of the new and conventional scoring systems for men's badminton singles in Taiwan. Journal of Exercise Science and Fitness, 6(1), 34-43.

Chen, K. Y., \& Bassett, D. R. (2005). The technology of accelerometry-based activity monitors: Current and future. Medicine and Science in Sports and Exercise, 37(Supplement), S490-S500. https://doi.org/10.1249/01.mss. 0000185571.49104 .82

Chu, E. Y. W., McManus, A. M., \& Yu, C. C. W. (2007). Calibration of the RT3 accelerometer for ambulation and non-ambulation in children. Medicine and Science in Sports and Exercise, 39(11), 2085-2091. https://doi.org/10. 1249/mss.0b013e318148436c

Cohen, J. (1988). Statistical power analysis for the social sciences. Routledge Academic

Cools, W., De Martelaer, K., Samaey, C., \& Andries, C. (2009). Movement skill assessment of typically developing preschool children: A review of seven movement skill assessment tools. Journal of Sports Science \& Medicine, 8(2), 154-168.

Craig, C. L., Marshall, A. L., Sjöström, M., Bauman, A. E., Booth, M. L., Ainsworth, B. E., Pratt, M., Ekelund, U., Yngve, A., Sallis, J., \& Oja, P. (2003). International physical activity questionnaire: 12-country reliability and validity. Medicine and Science in Sports and Exercise, 35(8), 1381-1395. https://doi.org/10.1249/01.MSS.0000078924.61453.FB

De Jonge, L., DeLany, J. P., Nguyen, T., Howard, J., Hadley, E. C., Redman, L. M., \& Ravussin, E. (2007). Validation study of energy expenditure and intake during calorie restriction using doubly labeled water and changes in body composition. The American Journal of Clinical Nutrition, 85(1), 73-79. https://doi.org/10.1093/ajcn/85.1.73

Dieu, O. (2012). Expérience corporelle et sens du mouvement: Matérialisationvia l'actimétrie du « contexte altéré par l'action » dans l'évolution du joueur de badminton. Staps, 98(4), 49. https://doi.org/10.3917/sta.098.0049

Dieu, O. (2015). Corrélation entre orientation tactique du jeu et quantité d'activité physique en badminton. eJRIEPS, 36[[En ligne], 99-120. https:// doi.org/10.4000/ejrieps.1481

Dieu, O., Vanhelst, J., Bui-Xuân, G., Blondeau, T., Fardy, P. S., \& Mikulovic, J. (2014). Relationship between tactics and energy expenditure according to level of experience in badminton. Perceptual and Motor Skills, 119(2), 455-467. https://doi.org/10.2466/29.PMS.119c21z3

Fahimi, F., \& Vaezmousavi, M. (2011). Physiological patterning of short badminton serve: A psychophysiological perspective to vigilance and arousal. World Applied Sciences Journal, 12(3), 347-353.

Faude, O., Meyer, T., Rosenberger, F., Fries, M., Huber, G., \& Kindermann, W. (2007). Physiological characteristics of badminton match play. European Journal of Applied Physiology, 100(4), 479-485. https://doi.org/10.1007/ s00421-007-0441-8

Gerdes, K. E., \& Stromwall, L. K. (2008). Conation:a missing link in the strengths perspective. Social Work, 53(3), 233-242. https://doi.org/org/10/fx249f

Gholar, C. R., \& Riggs, E. G. (2004). Connecting with students' will to succeed: Thepower of conation. Pearson Professional Development.

Hamill, J., \& Selbie, W. S. (2004). Three-dimensional kinematics. In D. G. E. Robertson, G. E. Caldwell, J. Hamill, G. Kamen, \& S. N. Whittlesey (Eds.), Research methods in biomechanics (pp. 35-52). Human Kinetics.

Hastie, P. A., Sinelnikov, O. A., \& Guarino, A. J. (2009). The development of skill and tactical competencies during a season of badminton. European Journal of Sport Science, 9(3), 133-140. https://doi.org/10.1080/17461390802542564

Hughes, M. (1998). The application of notational analysis to racket sports. In A. Lees, I. W. Maynard, M. Hughes, \& T. Reilly (Eds.), World congress on science and racket sports, science and racket sports II (pp. 229-238). E\&FN Spon.

Hughes, M., \& Franks, I. (2004). Notational analysis of sport: Systems for better coaching and performance in sport ( $2^{\mathrm{e}}$ éd ed.). Routledge. https://doi.org/ $10.4324 / 9780203641958$ 
Hughes, M. D., \& Bartlett, R. M. (2002). The use of performance indicators in performance analysis. Journal of Sports Sciences, 20(10), 739-754. https:// doi.org/10.1080/026404102320675602

Ibáñez-Gijón, J., Buekers, M., Morice, A., Rao, G., Mascret, N., Laurin, J., \& Montagne, G. (2017). A scale-based approach to interdisciplinary research and expertise in sports. Journal of Sports Sciences, 35(3), 290-301. https://doi.org/org/10/ggdkxr

Jaworski, J., Lech, G., Żak, M., Madejski, E., \& Szczepanik, K. (2017). The level of selected coordination abilities in badminton players at various ages and sport skill levels as compared to non-athletes. Baltic Journal of Health and Physical Activity, 9(3), 33-43. https://doi.org/10.29359/BJHPA.09.3.03

Knudson, D. V. (2013). Qualitative diagnosis of human movement: Improving performance in sport and exercise (3rd ed). Human Kinetics.

Kohavi, R., \& Provost, F. (1998). Glossary of terms. Machine Learning, 30(2), 271-274. https://doi.org/10.1023/A:1017181826899

Lantz, B. (2019). Machine learning with $R$ : Expert techniques for predictive modeling (1) (3rd ed.). Packt Publishing.

Lees, A. (2003). Science and the major racket sports: A review. Journal of Sports Sciences, 21(9), 707-732. https://doi.org/10.1080/ 0264041031000140275

Lieshout, K. A. V., \& Lombard, A. J. J. (2003). Fitness profile of elite junior badminton players in South Africa. African Journal for Physical, Health Education, Recreation and Dance, 9(3), 114-120. https://doi.org/10.4314/ ajpherd.v9i3.24643

Lorgnier, N., Su, C.-J., O'Rourke, S. M., \& Penel, G. (2018). Understanding conations in the organization: Multiple-level analysis and seasonality. International Journal of Sport Management, 1(19), 262-288.

Mather, G., \& West, S. (1993). Recognition of animal locomotion from dynamic point-light displays. Perception, 22(7), 759-766. https://doi. org/10.1068/p220759

Mikulovic, J., Bui-Xuân, G., \& Marcellini, A. (2002). Social and professional reintegration of the long-term unemployed disabled. Intervention on the body through adapted physical activities, conative teaching skills and social re-energization. International Journal of Rehabilitation Research, 25(1), 47-50. https://doi.org/org/10/bs6nmm

Ming, C. L., Keong, C. C., \& Ghosh, A. K. (2008). Time motion and notational analysis of 21 point and 15-point badminton match play. International Journal of Sports Science and Engineering, 2(4), 216-222.

Moore, A. W., \& Lee, M. S. (1994). Efficient algorithms for minimizing cross validation error. In H. Hirsh, \& W. W. Cohen, (Eds.), Machine Learning: Proceedings of the Eleventh International Conference: Rutgers University (pp. 190-198). New Jersey: Elsevier. https://doi.org/10.1016/B9781-55860-335-6.50031-3

O'Donoghue, P., \& Ingram, B. (2001). A notational analysis of elite tennis strategy. Journal of Sports Sciences, 19(2), 107-115. https://doi.org/10. 1080/026404101300036299

Phomsoupha, G., \& Dor, F. (2015). Changes in the game characteristics of a badminton match: A longitudinal study through the Olympic Game finals analysis in men's singles. Journal of Sports Science \& Medicine, 14(3), 584-590.

Phomsoupha, M., \& Laffaye, G. (2015). The science of badminton: Game characteristics, anthropometry, physiology, visual fitness and biomechanics. Sports Medicine, 45(4), 473-495. https://doi.org/10.1007/ s40279-014-0287-2

Raman, D., \& Nageswaran, A. (2013). Effect of game-specific strength training on selected physiological variables among badminton players. International Journal of Scientific Research, 10(2), 1-2. https://doi.org/10. $15373 / 22778179$

Reilly, T. (1990). The racket sports. In T. Reilly, N. Secher, P. Snell, \& C. Williams (Eds.), Physiology of sports (pp. 337-370). E \& FN Spon.
Schnitzler, C., Brazier, T., Button, C., Seifert, L., \& Chollet, D. (2011). Effect of velocity and added resistance on selected coordination and force parameters in front craw. Journal of Strength and Conditioning Research, 25 (10), 2681-2690. https://doi.org/10.1519/JSC.0b013e318207ef5e

Schnitzler, C., Button, C., Seifert, L., \& Croft, J. (2014). Analysing expertise through data mining: An example based on treading water. Journal of Sports Sciences, 32(12), 1186-1195. https://doi.org/10.1080/02640414.2013.876085

Seifert, L., Araújo, D., Komar, J., \& Davids, K. (2017). Understanding constraints on sport performance from the complexity sciences paradigm : An ecological dynamics framework. Human Movement Science, 56(A), 178-180. https://doi.org/org/10/gctgrr

Seifert, L., Button, C., \& Davids, K. (2013). Key properties of expert movement systems in sport: An ecological dynamics perspective. Sports Medicine, 43(3), 167-178. https://doi.org/10.1007/s40279-012-0011-z

Seifert, L., Orth, D., Mantel, B., Boulanger, J., Hérault, R., \& Dicks, M. (2018). Affordance realization in climbing: Learning and transfer. Frontiers in Psychology, 820(9), 1-14. https://doi.org/org/10/gdn3nf

Silva, P., Santiago, C., Reis, L. P., Sousa, A., Mota, J., \& Welk, G. (2015). Assessing physical activity intensity by video analysis. Physiological Measurement, 36(5), 1037-1046. https://doi.org/10.1088/0967-3334/36/5/1037

Smeeton, N. J., Ward, P., \& Williams, A. M. (2004). Do pattern recognition skills transfer across sports? A preliminary analysis. Journal of Sport Sciences, 22 (2), 205-213. https://doi.org/10.1080/02640410310001641494

Taylor, M., \& Hughes, M. (1998). Analysis of elite under-19 tennis players. In A. Lees, I. W. Maynard, M. Hughes, \& T. Reilly (Eds.), World congress on science and racket sports, science and racket sports II (pp. 211-220). E\&FN Spon.

Tiwari, L. M., Rai, V., \& Srinet, S. (2011). Relationship of selected motor fitness components with the performance of badminton player. Asian Journal of Physical Education and Computer Science in Sports, 5(1), 88-91.

Vanhelst, J., Béghin, L., Duhamel, A., Bergman, P., Sjöström, M., \& Gottrand, F. (2012). Comparison of uniaxial and triaxial accelerometry in the assessment of physical activity among adolescents under free-living conditions: The HELENA study. BMC Medical Research Methodology, 12(1), 20-26. https://doi.org/10.1186/1471-2288-12-26

Vanhelst, J., Béghin, L., Fardy, P. S., Bui-Xuan, G., \& Mikulovic, J. (2012). A conative educational model for an intervention program in obese youth. BMC Public Health, 12(1), 416-421. https://doi.org/10.1186/1471 2458-12-416.

Vanhelst, J., Béghin, L., Rasoamanana, P., Theunynck, D., Meskini, T., Iliescu, C., Duhamel, A., Turck, D., \& Gottrand, F. (2010). Calibration of the RT3 accelerometer for various patterns of physical activity in children and adolescents. Journal of Sports Sciences, 28(4), 381-387. https://doi. org/10.1080/02640410903508821

Vanhelst, J., Fardy, P. S., Béghin, L., Bui-Xuan, G., \& Mikulovic, J. (2013). Strategies in intervention programmes for obese youth : Implication of the age and the type of physical activities. Clinical Physiology and Functional Imaging, 35(1), 17-20. https://doi.org/org/10/ggdk2s

Wang, J., \& Liu, W. (2012). Changes in badminton game play across developmental skill levels among high school students. ICHPER-SD Journal of Research, 7(2), 29-37. https://doi.org/10.1080/07303084.2017.1356768

Wang, J., Liu, W., \& Moffit, J. (2009). Steps for ARM and trunk actions of overhead forehand stroke used in badminton games across skill levels. Perceptual and Motor Skills, 109(1), 177-186. https://doi.org/10.2466/pms.109.1.177-186

Wang, J., \& Moffit, J. (2009). Teaching badminton based on student skill levels. Strategies, 22(6), 14-18. https://doi.org/10.1080/08924562.2009. 10590844

Williams, A. M., Hodges, N. J., North, J. S., \& Barton, G. (2006). Perceiving patterns of play in dynamic sport tasks: Investigating the essential information underlying skilled performance. Perception, 35(3), 317-332. https://doi.org/10.1068/p5310 